\title{
Nursing Practicums in Health Promoting Schools: A Quality-Improvement Project
}

\author{
Kasha Mcharo \\ University of Saskatchewan, kasha.mcharo@usask.ca \\ Kerry Marshall \\ University of Saskatchewan, KMM734@mail.usask.ca \\ Wanda Martin \\ University of Saskatchewan, wanda.martin@usask.ca \\ Brent Rioux \\ Saskatchewan Health Authority, Brent.Rioux@saskhealthauthority.ca
}

Follow this and additional works at: https://qane-afi.casn.ca/journal

Part of the Public Health and Community Nursing Commons

\section{Recommended Citation}

Mcharo, Kasha; Marshall, Kerry; Martin, Wanda; and Rioux, Brent (2021) "Nursing Practicums in Health Promoting Schools: A Quality-Improvement Project," Quality Advancement in Nursing Education - Avancées en formation infirmière: Vol. 7: Iss. 1, Article 4.

DOI: https://doi.org/10.17483/2368-6669.1259

This Article is brought to you for free and open access by Quality Advancement in Nursing Education - Avancées en formation infirmière. It has been accepted for inclusion in Quality Advancement in Nursing Education - Avancées en formation infirmière by an authorized editor of Quality Advancement in Nursing Education - Avancées en formation infirmière. 


\section{Nursing Practicums in Health Promoting Schools: A Quality-Improvement Project}

\section{Cover Page Footnote}

Funding was provided by the Saskatchewan Health Authority to support this work. Cette initiative a été rendue possible grâce au financement offert par la Saskatchewan Health Authority. 


\section{Nursing Practicums in Health Promoting Schools: A Quality-Improvement Project}

Some nursing students (learners) view practicum experiences in community health as something to experience in the process of becoming a "real nurse." Nursing programs access schools for community practicums even though the full-time role of school nurse no longer exists in most school settings in Canada (Kirk, 2020), a casualty of the general eroding of public health systems and services (Guyon et al., 2017). The devaluing of public health and lack of public health nursing positions can create challenges when educating new nurses on primary prevention and population health promotion. To understand the challenges and improve the efforts to educate new nurses on community health, we conducted a quality-improvement project with nursing learners in elementary health-promoting schools from a service-learning perspective.

\section{Background}

Service learning provides an excellent opportunity for students to observe first-hand the factors that contribute to health disparities (Thomas \& Smith, 2017). It gives learners experiential opportunities in real-world contexts and time to develop community engagement skills while affording community partners' ways to address significant health needs (Bandy, 2020). Through service-learning platforms, students engage with stakeholders to create mutually beneficial outcomes, enriching their experience through the learning process (Juniarti et al., 2017). Service learning provides students with opportunities to gain practical knowledge and learn civic responsibility while helping community members (Bandy, 2020).

Nursing schools have used service learning as a tool for developing cultural competence (Amerson, 2010; Worrell-Carlisle, 2005), for improving nursing proficiencies (Vogt et al., 2011), and for promoting leadership and social justice (Groh et al., 2011). With service learning, learners can see how poverty, lack of access to health care, difficulties with public transportation, behavioural factors, gender, sexual orientation, and a lack of educational opportunities can contribute to health disparities (Thomas \& Smith, 2017). As a result, learners acquire an increased sense of self-efficacy, learn cultural competence, believe fewer stereotypes, and can develop interpersonal skills, citizenship, social responsibility, critical thinking, and connectedness to the nursing profession (Worrell-Carlisle, 2005).

To provide service learning, nursing educators reach beyond the classroom and traditional health care settings to provide learners with opportunities to work with diverse populations (Murray, 2013). Service learning is incorporated into a course through a project that has both learning and community action goals designed via collaboration between faculty and community partners (Bandy, 2020). Schools are an example of such community partners.

Schools are often community hubs with opportunities for social development and services beyond education (Horn et al., 2015). Schools are a venue in which new nurses can learn about the principles of primary health care and population health promotion. In some nursing practicums, learners are placed with health-promoting schools, which use the Comprehensive School Community Health framework (World Health Organization, 1997). The framework includes initiatives focused on the social and physical environment, teaching and learning, family and community engagement, and healthy school policy (Joint Consortium for School Health, 2020). Physical activity, healthy eating, and positive mental health programs that adopt the comprehensive school health model are effective in shaping positive health behaviours of schoolchildren (Barnekow et al., 2006). Schools using the framework have a health-promoting schools' teams. In many schools, the team includes the public health nurse or practicum supervisor, 
adult allies (parents and teachers), and student leaders. The nurse learners are also part of the team. Schools with a health-promoting schools' teams are supported by the health authority to set up the team and apply the Comprehensive School Community Health framework.

There is sparse literature on the nursing practicum experiences in community health settings (Laliberte et al., 2017). Laliberte et al. (2017) evaluated nursing community practicums with a population health-promotion focus and found having such experiences as an essential foundation for being a registered nurse. The Canadian Association of Schools of Nursing (CASN) also requires registered nurses to acquire community health nursing knowledge and skills by having a strong community clinical practice component in their nursing education program (CASN, 2010). Health-promoting schools benefit from having nursing learners as there are more people to help manage programs and engage with youth (Thomas \& Smith, 2017). Similarly, we suspected that nursing learners benefit from being in these schools. Yet we were not clear on the extent that both the school and the nursing learner benefit from this mutually supportive arrangement.

Juniarti et al. (2017) provided a service-learning framework in nursing education that discussed four components: (1) a structured form of intracurricular experiential learning, the preparation that occurs before the placement of nursing learners; (2) reflection, in which learners make meaning of their experiences; (3) reciprocity, in which all stakeholders function as both teachers and learners with partnership and collaboration; and (4) the setting of specific outcomes and benefits of service-learning for the stakeholders. The purpose of this paper was to explore nursing learners' community clinical experience in health-promoting schools using a servicelearning framework for quality improvement of nursing education.

\section{Methods}

At the request of the local health authority health-promoting schools' teams, we conducted this quality-improvement project using three inner-city elementary schools in a mid-size Canadian city. We present data collected between January and April of 2019 from 24 fourth-year nursing students and three principals from selected health-promoting schools. We used purposive sampling to select participants. The intent was not to share new information or to develop new knowledge, but to review the experience of nursing students in health-promoting schools to identify the benefits and challenges with a view to a potential expansion of the service-learning arrangement. The lead author contacted the nursing learners and the school principals to explain the purpose of the project and conducted face-to-face 30-minute semi-structured interviews with volunteers. The project team and health-promoting schools' team jointly developed the questions. Conversations were audio recorded with the informants' verbal consent. Because we designed this as a qualityimprovement nursing project, the ethics committee confirmed that the project was exempt from review. However, participants were fully informed, and interviews were conducted according to the principles of the Declaration of Helsinki.

We used Clarke and Braun's (2013) six-phase thematic analysis process for data analysis: (1) familiarizing by immersion in the data through listening to the audio recordings, conducting a verbatim transcription, and rereading the data; (2) coding by constant comparative analysis, generating brief labels for important features relevant to the broad evaluation purpose; (3) searching for themes, recognizing coherent, meaningful patterns by grouping similar codes together, and finding labels to summarize the data in short phrases; (4) reviewing themes and collapsing groups of codes, reflecting on whether the respondents told the same story; (5) defining 
and naming themes to capture the essence; and (6) writing up by weaving together the analytical narrative, using a service-learning framework as described by Juniarti et al. (2017) to present underlying themes in the data. We attended to trustworthiness by being reflexive through memos and team discussions with members who have prolonged engagement in the setting (credibility) and seeking different data sources to observe various perspectives (transferability). While the primary author led the analysis, all authors discussed and reviewed the process.

\section{Service-Learning Context}

The first component of service learning is a structured form of intracurricular experiential learning (Juniarti et al., 2017). This component entails assessment, planning, implementation, and evaluation of the service-learning experience. Nursing learners were enrolled in a community health practicum concurrently with community health theory in their final year of studies. The theory lecture provided topics applied in real-life clinical experiences that addressed community health. Nursing learners typically had an introduction to the social determinants of health in the second year of their education. Not all community practicums are with schools, and not all schools that accept nursing learners are health-promoting schools. Four groups of seven learners were placed in urban health promoting schools for 12 weeks. All schools were public community schools for kindergarten to grade 8 students. All the schools were inner-city schools serving a similar socioeconomic population and provided similar learning experiences for nursing students. Nursing learners were expected to provide community health teaching, engage in school health activities, perform class health assessment, and work closely with the school community health coordinator to determine the needs of the school and the surrounding community.

\section{Results}

The focus of this project was to consider how both the nursing learners and the healthpromoting schools benefit from nursing learners being in the institutions. Several themes emerged from the interviews, including experiencing something new, creating meaning through reflection, achieving reciprocity, and providing direct benefits to stakeholders.

\section{Experiencing Something New}

Nursing learners acknowledged that a community health practicum had unfamiliar roles and expectations compared to their acute care settings from third year. Additionally, they recognized that community health had a more fluid structure since their goals and expectations kept changing according to their familiarity and assessments. One learner stated:

When we first came in, we sort of jumped right into our teaching, after one week, which I think was a good way to start us off. That was a good way to do it. I wasn't even sure what we were doing, like the first half, I was just like "what am I doing?" And maybe not understanding.

Although the nursing learners had theory lectures on community health, most felt it would have been beneficial if they had received more lectures and seminars on health-promoting schools before the practicum. For most learners, this is the first exposure to implementing programs, and it may be challenging to learn the content and the context to design and implement an intervention in the timeframe provided learners in this practicum. Regardless, the health-promoting schools' team at the school considered nurses to be full partners. Learners took part in decision making, planning, and implementing some of the school health promotion initiatives.

\section{Creating Meaning through Reflection}


Reflection is a practice where stakeholders process and ponder on their service-learning experience and create meaning (Juniarti et al., 2017). For some nursing learners, the aim of reflection is to improve critical thinking and promote caring behaviour. Reflection is achieved by three means: observation, which involves the perceptions of stakeholders in relation to what they learned and achieved in the service-learning activities; analysis, which is conducted through conversation and discussion of the service-learning experience; and synthesis, which can be used as a basis for future application (Juniarti et al., 2017). Stakeholders identified in this project were school principals and nursing learners. Confidence building, improved relationships, improved cultural awareness and sensitivity, application of an integrated approach, and perceived challenges were areas that surfaced through reflection.

\section{Confidence Building}

Nursing learners identified positive feedback and interactions with health-promoting school's staff as instrumental in developing their confidence. Nursing learners also recognized that their interactions with the students, the class teachings, and the planning and implementation of initiatives contributed to the improvement of their confidence throughout the practicum. One nursing learner stated:

I have been able to build my confidence from speaking in front of student groups, something we haven't really done a lot of in nursing school and even there I'd get anxious. Interacting with different people, I'll take that with me as well.

In this practicum, nursing learners reflected on the school staff as supportive, open to new ideas, willing to provide feedback on ideas, valuable sources of information, and gatekeepers in building community relationships. The active involvement of school staff validated the nursing learners' initiatives, encouraging them to realize their objectives.

\section{Improved Relationships}

Nursing learners reflected on how this community practicum allowed them to learn how to build relationships with children and improved their overall communication with children, parents, and staff. Nursing learners considered that learning how to communicate with children and their parents was valuable knowledge to their future interactions with pediatric patients and caregivers. Reflecting on her interactions with students, one nursing learner described:

Children are always looked down upon where they are seen and not heard and I kinda grew up in that situation too so now with practice and everything its coming down to their level and being able to understand that they are very smart, they're smarter than some people give them credit for, so communication is just key to any relationship. And like I said before, its taking the time out of your day just to have a conversation with somebody opens those doors to maybe self-regulation for themselves as well as being able to take in the information that you're giving them instead of focusing on themselves.

Nursing learners improved their relationships by learning how to communicate effectively through offering empathy and being friendly with the students, staff, and parents. Displaying a genuine concern for the students' mental and physical well-being also contributed to improved relationships. As a result of improved relationships, nursing learners established trusting relationships, students were more engaged, and nursing learners and school staff were better able to rely on each other as team members.

\section{Cultural Awareness}


Nursing learners recognized that students came from different ethnic and cultural backgrounds that influenced their values and beliefs about health. This cultural awareness enabled nursing learners to have a better understanding of the communities' health choices, encouraging learners to be more culturally sensitive. Nursing learners recognized cultural awareness as beneficial for future practice by knowing that community members seeking care in hospitals are of different cultures and often hold different values from their own. Responding to how the community health practicum benefited her, one nursing learner stated, "Being culturally sensitive and aware is the most beneficial thing-with all different backgrounds and populations of people from [this area], knowing they have different things that affect their health." Exposure to student diversity challenged nursing learners to better understand the importance of being culturally responsive in both individual care and the approach to implementation of community health initiatives. This provided nursing learners with the opportunity to challenge their own worldview and understand other worldviews and life circumstances.

\section{Perceived Challenges}

Reflection on service-learning allowed nursing learners to identify areas that could improve their community health practicum experience and benefit the health-promoting schools and community. Nursing learners recognized a need for more teaching on mental health in the schools they attended. Close interactions gave nursing learners an opportunity to observe inappropriate behaviours, such as bullying, offensive language, and sometimes self-isolation among the students. In some cases, students would confide in nursing learners with whom they felt comfortable. To address the mental health issues, nursing learners joined small groups of students, shared meals with them, and organized classes to tackle concerns students were facing. Reflecting on the need for more mental health education, one nursing learner stated:

I think a lot more lessons on mental health need to be done. My thinking is like, it just feels like there is this huge gap and nobody is focusing on these children and they're not giving them the tools at this age. They're not giving them the teaching lessons that they need to do after school and that's why I feel like there are so many mental health issues and nobody is focusing on the young right now.

Although one part of their practicum objectives was to address the mental health of students, nursing learners identified a perceived gap in mental health promotion and observed the need for more dedicated resources to extensively support a comprehensive approach to address mental health concerns. Nursing learners also identified that the school's nutrition policies required improvement. Nursing learners noted frustration when efforts to implement change were met with resistance from school staff. One participant stated:

One thing we struggled with in this community was nutrition because the school doesn't really have a nutrition policy, like a no junk food policy, so that's where most of the conflict came from with staff. They're pressed [for] money and resources, so they'd sell pop and chips when we know those things are not good for child development. So, it was hard for us as students to try and implement that when it's not a policy in the school ... I think that's just something that's lacking in this school.

While all schools in the province have an overarching nutrition policy or administrative procedures, having a nutrition policy specifically around high-calorie, low-nutrient foods would ensure all stakeholders are committed. The issue of nutrition is reflective of a larger problem with food environments and food insecurity. Supporting staff in implementing healthy food choices can 
greatly contribute to the school food environment. Schools are challenged in adhering to healthy school food environments given the ease and acceptability of packaged and low-nutrient foods in North American society. The realization for nursing learners was that building a healthy food environment is much more than a policy and requires engagement and co-creation by staff, parents, and students.

Last, nursing learners identified gaps in their curriculum that educators could improve for better service-learning outcomes. Learners suggested that the community practicum should occur earlier in their clinical experiences to give them a better understanding of the community they will be serving in both acute and community settings. Nursing learners also identified lack of continuity in evaluating the initiatives they started as a challenge in their service-learning experience. For example, because nursing learners had 12 weeks for the community health practicum, it was difficult to evaluate the impact of the support nursing learners offered. As one nursing learner elaborated:

I wish we could have done more to enhance the parental engagement; I wish we could do more to promote the continuity of care. Because it seems like we have an impact while we are here, but when we are gone how can we be sure that continues? How can we be sure that when they go home that they retain that knowledge and it gets applied? Figuring out what can continue even when you are not present. It's really nice like what we are doing while we are here but like when we are gone, what kind of message can we leave them that they will hopefully retain and even get their parents involved and take it home?

While learners often have commented that the nursing program should offer a course earlier, it is not always feasible to do so. That observation does, however, indicate the value of understanding the community for providing more effective tertiary care, and building that into nursing programs early can influence experiences in acute care rotations.

The school principals also identified a lack of continuity after the nursing learners leave the schools as a challenge they experienced. As one principal stated:

We really get the groove and then it's time to leave and I get it, it's a practicum. The important thing is they got to feel it's important and we got to feel it makes a difference with our kids and I think it does.

Involving the staff in establishing yearly health promotion goals was beneficial because it helps identify priorities and ensures continuity of established goals. One principal acknowledged that principals need to be more present and work closely with nursing learners and health-promoting school staff to guarantee continuity of established goals.

\section{Achieving Reciprocity}

Reciprocity is a process in which all the stakeholders learn from each other (Juniarti et al., 2017). In reciprocity, partnerships result in mutual benefits, transforming learning, behaviour, and the community. Three areas surfaced as important in achieving reciprocity: health education, role modelling, and community awareness.

\section{Health Education}

Nursing learners considered themselves as sources of information for schools in matters concerning health. As part of their practicum, nursing learners provided mental health education, which centred on student behavioural coping skills, anti-bullying, self-expression, healthy 
relationships, and conflict resolution. Other health topics included personal hygiene, self-care, sexual health, and infectious diseases. Nursing learners worked closely with the health-promoting schools' teams to share their expertise through interacting with the parents and engaging the community through different community events. When explaining their role in health promoting schools, one nursing learner stated:

I guess everything we've done here has been designed that it has some health-promotion value behind it. But we just did the mental health conference, just finished health teachings on HIV/diabetes, infectious diseases - the more actual nursing side of it.

In providing health education, nursing learners had an interdisciplinary experience as they had to work with the teachers and school community coordinators to tailor the teachings to address their class needs. Nursing learners also benefited from planning community events, which exposed them to working under pressure in a community context, developing their presentation skills, and building resilience when things did not go as planned. The health-promoting schools' teams, which involved the principal, the community health coordinator, and an assigned staff member, also regarded nursing learners as "expert resources." Other than being expert resources, providing health education, and interacting with the children in small groups, nursing learners individually provided much-needed psychosocial support for the students. Acknowledging the value of the nursing learners to the health-promoting schools and their working relationship, one principal explained:

I always think of a triangle - home, health, and education — with the child at the middle. A lot of the time the triangle doesn't communicate. Home communicates with education, health communicates with home, but a lot of time health and education don't communicate. Having the nursing students here and at that school you realize the importance of it. It is more important than them coming in and talking about healthy eating, germs, and brushing your teeth. That, however, leads them into what they need to do in the classroom at the superficial level. The big thing is working with our kids in the mental health level, and it is affecting education more and more.

This principal recognized the added value of nursing learners to help with the mental health challenges in this school.

\section{Role Modelling}

Nursing learners felt a great need to set examples for students while being better versions of themselves. Nursing learners demonstrated role modelling by spending more time talking to students, refraining from food and snacks they would normally eat, or quitting some habits they deemed unhealthy:

I taught health lessons. I set examples for children - in fact, I even took it as far as quitting smoking ... Taking into account them having a role model or somebody there, I would spend lots of time in after school programs, I would structure my lessons to include some of the children who were a little further behind so that they could feel part of things. I would eat my lunch with the kids quite a few days, just showing them that I am eating healthy meals, showing them that I am eating that salad, as much as they'd come up and say, "Ew, salad," but you know setting that example.

For role modelling to occur, nursing learners recognized that positive relationships and connections were important both in the community and at the personal level. Nursing learners and 
students had to establish trust to achieve positive relationships. As one nursing learner indicated, "Being in the community helps you to see how important it is to build, develop and maintain those relationships because without those relationships you can't do anything with your clients." A trusting relationship led to a positive teaching and learning experience. As part of a healthpromoting school, nurse learners realized the importance that adults being role models of healthy behaviours.

The health-promoting school's adult team members also acted as role models to nursing learners. Nursing learners acknowledged benefiting from observing how the staff engaged with their students, parents, and community stakeholders. While monitoring interactions between members of the health-promoting school's adult allies team and community members, nursing learners became familiar with the protocol and patience necessary in this work, acquired problemsolving skills, and reinforced the importance of setting priorities in community contexts. Nursing learners also became acquainted with factors influencing decision-making processes. One participant described how the community coordinator made the final decision regarding community initiatives and observed how her decisions were based on available funds and supplies:

With the community coordinator it's a lot of planning. We collaborate with her just to make sure everything goes smoothly throughout the week. She's been here for a while, so she's really smart when it comes to knowing what will work with the kids and what doesn't, what budget she has, what supplies she has. So, she is really set with what she wants to happen with the kids. Once she directs us with what she wants us to teach, it kinda goes back to us. Our ideas are encouraged but they are limited to the resources available ... She encourages us to give ideas. She says she might say no to you a couple of times but keep giving the ideas.

\section{Community Awareness}

Nursing learners expressed that service learning gave them a better understanding of the community in which they worked, the challenges they faced, and the community resources available for public health. For some First Nations' nursing learners, working in complex-needs' schools equipped them with tools to implement change in their home reserve schools and advocate for change. A better understanding of the community inspired some nursing learners to be advocates for social justice. One nursing learner commented:

I have a passion for injustices, disparities, inequities. So, using what I learnt here, being in the school and actually with the kids, and using that as a force to bring that knowledge out, because I plan to be getting into community position. So, having that knowledge and understanding is really beneficial and valuable knowledge needed in that area.

Working in schools allowed nursing learners to interact and sometimes work closely with community stakeholders. These interactions facilitated nursing learners' recognition of the unpredictability of community health nursing and the necessity of adapting to provide the care needed by the school and community.

\section{Setting Specific Outcomes and Benefits}

For service learning to be valuable, emphasis should be focused on setting specific outcomes and benefits for all stakeholders (Juniarti et al., 2017). Examples of specific outcomes reported by Juniarti et al. (2017) include competencies and insights into certain values for learners,

health-related outcomes for clients and the community, and cost-effectiveness in providing 
services for partner organizations. Primary prevention interventions, understanding of the social determinants of health, and human resources are the three themes in setting specific outcomes and benefits for stakeholders.

\section{Primary Prevention}

Nursing learners identified health promotion and disease prevention as one of their primary roles in the health-promoting schools. The strategy implemented by nursing learners for primary prevention was mainly health education. Nursing learners provided education about healthy and safe habits through various community initiatives, such as health fairs. Recognizing the significance of primary prevention, one nursing learner stated:

After coming from a high acuity placement, now I see more of the community standpoint. Not being in scrubs and not treating an illness but rather I can approach it from a primary approach where I am working with the kids where I can address and prevent those behaviours before it reaches a point where they need that professional intervention in the hospitals.

Nursing learners displayed their adaptability and willingness to work in different community settings to be of service to the community. Furthermore, the presence of nursing learners in the health-promoting schools acted as a reminder to the children, staff, and community of the value of living a healthy lifestyle. Health-promoting school principals observed that nursing learners provided health education to parents who would seek them out for advice on their health. Through service learning in a community health practicum, nursing learners and principals appreciated how working together as a health-promoting school could encourage healthy lifestyle choices through the school's nutrition program and a school curriculum that emphasizes health education.

Principals also benefited from fresh, innovative ideas raised by nursing learners and acknowledged that service learning contributed to more collaboration between the health region, education, and social services. This collaboration ensured a more effective preventive approach rather than relying on a curative approach. Talking about the health-promoting school program, one principal stated:

This is an example of a successful program when we work with the health region, education, social services, and justice. I think if all those people could get on the same page, we could support youth and impact them earlier on if we would all come and work together. I think right now we are reactionary, we put a lot of money and resources into the back end of things. I think if we would work together earlier with children and families, we would see better outcomes later on.

To further promote primary prevention with learners, the principals described an ideal approach that involved specialized support by learners from different disciplines, such as public health, community health nursing, or social services. Principals argued that an interdisciplinary approach to primary prevention had better health outcomes in the community since the experts were in a better position to provide suitable and informed strategies to education in their respective areas.

\section{Understanding of the Social Determinants of Health}

Nursing learners highlighted how service learning reinforced their understanding of social determinants of health and the impact of health-promoting schools in the community. Working in inner-city communities revealed a vivid picture of how social determinants of health affect behaviour, education, and health in children and the community at large. One learner stated: 
I guess one big thing that I have found working in this school and the community is it really puts a tangible perspective on social determinants of health and inequities, and like, upstream forms of prevention, so like, working in schools is so important to prevent [those more vulnerable] from coming into hospitals.

Most nursing learners were from a more affluent part of the city, and this community placement allowed them to interact with children and members of an inner-city community. Being in complex-need schools enabled nursing learners to experience firsthand the context of students' lives and the impact social determinants had on health, education, and well-being. This experience led nursing learners to be less judgmental and more empathetic in their dealings with students and community members.

\section{Human Resources}

Having nursing learners in health-promoting schools provided extra people to assist in supporting students and staff. This provided capacity to adequately perform tasks, generate ideas, and organize and implement school health-promotion initiatives. For instance, the addition of more personnel was beneficial in the nutrition program, where nursing learners were involved in the preparation and distribution of meals within the school. Another apparent benefit was in delivering health education classes incorporated into the school curriculum. The school principals also acknowledged that the nursing learners multiplied the capacity organize school events such as health fairs, which were beneficial to students and the community. As one of the principals noted:

Now with the nursing students, that's a very good model as they are embedded into the schools with a nurse and then of course a handful of students. I have had anywhere between three and six nursing students. That provides the extra human resources, allowing us to connect more of the health outcomes with the school curriculum. Some examples of that would be, I've had to talk about the importance of sleep. A lot of our kids are gaming at night and are not getting good sleep. So currently that is what some of the nursing students are working on. Another example would be supporting the sexual health outcomes in our health curriculum. It's nice to bring in kind of more trained people for that. Our teachers can do that, and have done that, but it's nice to have people come in to do that.

Nursing learners added capacity to help identify specific health needs of students and tailor their intervention to the common health issues. Personalized care allowed nursing learners to prioritize the needs of the student, promote inclusion of other supportive staff such as school counsellors, and eased follow-up care with the students' caregivers.

\section{Discussion}

The objective of this evaluation was to articulate the role and contribution of nursing learners in health-promoting schools and to identify the extent of mutual benefits for nursing education and the school environment with a view to enhancing the quality of the service-learning opportunity. Our findings indicate that service learning in health-promoting schools supports the understanding and application of fundamental community health nursing concepts, leading to enhanced caring. Caring is a concept that is central to the nursing discipline (Newman et al., 2008). Within nursing curricula, effective communication and presence play an important role in developing caring behaviours (O'Brien King \& Gates, 2007). O'Brien King and Gates (2007) contend that caring behaviour involves not only service to others but also an intrinsic evaluation of self. Arguably, teaching caring is difficult. Service learning creates an opportunity for nursing 
learners to nurture caring behaviours through reflection on self in the context of service to others, challenging personal assumptions and beliefs (Schofield et al., 2013). This practice of selfknowing and caring was evidenced by nursing learners' awareness of their position as role models for the students and the community. Community health practica in health-promoting schools allow nursing learners to reflect on concepts central to the nursing discipline since valuable relationships are formed with the self, the school, and the community. Additionally, service learning within health-promoting schools enables nursing learners to have a practical experience in observing the social determinants of health and examining the social determinants' influence on the mental, physical, and emotional health of elementary school children. This first-hand experience also allows nursing learners to be aware of social, political, cultural, and economic influences that determine the well-being of a community. Subsequently, nursing learners' caring behaviours are reinforced and a need for social justice is cultivated as a holistic understanding is achieved (Carnicelli \& Boluk, 2017).

Service learning through community health placements in health-promoting schools provides an opportunity to refine nursing learners' non-technical interpersonal skills, which are essential in nursing practice. There may be a lack of education on interpersonal skills in traditional nursing curricula, and students may lack competence moving forward into the work world (Lau \& Wang, 2014). From our exploration, nursing learners identified health-promoting schools and community health placements as opportunities to become more comfortable and proficient in interpersonal skills. Nursing learners improved their communication skills, developed teamwork skills, built confidence, and cultivated responsibility and leadership, characteristics that are vital in nursing practice. Although other authors have argued that service learning is labour intensive and takes much student time and energy, questioning its impact and benefit to stakeholders (Cohen \& Milone-Nuzzo, 2001), our participants suggested that the skills developed in this type of experience are a highly valuable part of nursing education and nursing practice.

Health-promoting schools give nursing learners an opportunity to understand and implement primary prevention strategies within the school and community for better social and health outcomes. For example, nursing learners were positioned to identify challenges within family units that potentially could interfere with a youth's ability to learn. Nursing learners can emphasize primary prevention approaches through mental health lessons with youth. Consequently, service learning in health-promoting schools provides an opportunity for early intervention with mental health challenges, showcasing health promotion, developing upstream thinking, and addressing the root causes. In addition to supporting mental health, nursing learners can address physical health, encouraging prevention of lifestyle diseases, such as obesity and type 2 diabetes, which has become increasingly prevalent in children (Spurr et al., 2017). Nursing learners, in collaboration with community leadership, can be instrumental in implementing healthpromotion strategies through health education. Additionally, through portraying caring behaviours and building relationships with youth, nursing learners can potentially identify and address specific challenges affecting youth, such as substance use, which can lead to health challenges, ultimately impacting the health of the community. Service learning in health-promoting schools encourages nursing learners to think critically about primordial and primary prevention strategies while providing hands-on experiential learning opportunities for health promotion in the community.

Findings from this exploration underscore nursing learners' initial uncertainty in their role and expectation as nurses in community health practicums. Nursing learners often have a lesser preference for a community health practicum since it lacks the hands-on or hard skills nursing 
experience encountered in acute care (Murphy et al., 2012). It is not uncommon for nursing learners to be unclear about their role and expectations when undergoing community health practicums (Leh, 2011). However, this lack of clarity could reflect a greater societal and academic focus on acute care and treatment of disease in the biomedical model, as opposed to health promotion and prevention strategies. While the benefits of a focus on community health are becoming more apparent within society (Shelton \& Harrison, 2011), community health nursing arguably remains the most critical aspect of the health care system that lacks understanding. Community health nursing risks being lost because of nurses being absorbed into the highly acute care focused medical model (Kirk, 2020). Consequently, comprehending the value of community health practicums can be difficult for nursing learners, and the concepts can be challenging to grasp. Service learning within health-promoting schools acts as a bridge in understanding community health theory and practice. It provides a structure for nursing learners to better understand fundamentals of community health nursing and a practical justification to community health practicums.

Service learning has reciprocal and mutual benefits for all stakeholders: nursing learners and students, their respective academic institutions, and the community. To achieve long-term health outcomes, nursing schools should foster a collaborative approach and partnerships between the academic institutions and the community stakeholders to integrate nursing service learning into the health-promoting schools' framework more broadly. Furthermore, if nursing learners have a clear understanding of their roles and expectations, they can contribute more and become valued members of the team. Established goals, a team approach, and mentorship enhance nursing learners' experience in community health practicums since nursing learners feel they are part of a team with positive role models and mentors (Murphy et al., 2012).

\section{Conclusion}

The erosion of public health in Canada and inability to have public health nursing practicums in some Canadian provinces may have a trickledown effect to nursing learners. The opportunity for learners to be in health-promoting schools may help to correct the negative impression some learners have of community health nursing. Applying a service-learning framework may validate, legitimize, and solidify the importance of community health professionals being accessible within schools and may provide more opportunities for health care professionals to be within these schools. Additionally, with the service-learning approach, more social programs could incorporate nurses and learners to serve the community better.

\section{Limitations}

Nursing educators did not make learners aware of the service-learning framework before their clinical practicum. Providing this intention of service learning as a basis for their clinical program may have resulted in a different level of self-reflection and understanding of the practicum. Considering some nursing learners experience confusion in the transition from acute care to community health, understanding the framework may be beneficial. Additionally, we limited this evaluation to fourth-year nursing students, who have a greater capacity for higherlevel thinking on social determinants of health and health complexities as compared with earlier years in nursing education. While the practicum represents a consolidation of nursing knowledge, there could be different results with learners in earlier years.

\section{Quality Improvement}


The results of this project are with the health-promoting schools' teams at the health authority and with the faculty leading the community health practice and theory courses. This project provides important context for the nursing learners who are moving into schools as their community placements. Nursing instructors can use this information to better prepare students who have traditionally been reluctant to take on school learning opportunities. Furthermore, this work provides valuable information for health authorities to improve service-learning opportunities for nursing students.

\section{Implications for Nursing Education}

Nursing education programs are often highly focused on the technical skills that are typically associated with acute care settings. Important nursing skills, such as interpersonal skills, may be considered less teachable. Caring is a concept central to the nursing discipline, and valued interpersonal skills need to be practised - an excellent way for learners to achieve these skills is in placements in schools. Considering there is a misunderstanding of what community health offers, and learners may believe there are few skills to learn (Shelton \& Harrison, 2011), providing learners with a solid framework and understanding of the importance of community health is essential.

Nursing learners expressed having unclear expectations of what the clinical placement would entail, reducing the quality of the educational experience. Therefore, it is important to strengthen preparation for community clinical placements, yet that is challenging in curriculum development (Shelton \& Harrison, 2011). Understanding service learning can promote nursing learners' comprehension of community health and the benefits of this work. Recognizing the importance of community health, holistic care, and root causes of disease are imperative to have learners appreciate the importance of the community clinical practicum experience.

Furthermore, there is opportunity to strengthen and improve the school setting. To meet the goal of quality improvement, we recommend having consistent mentors, both within the schools and the nursing program, who are strong in communication and clear in expectations to provide support for learners. Consistency with clinical instructors and strengthening of the adult team at the schools can achieve these recommendations. Last, continuity can be an important factor when working with multiple teams and with vulnerable communities. It may be helpful to consider having learners write up their work and next steps and to pass those to the next clinical group. Continuity can also be achieved through having strong mentorship within the nursing faculty, clinical instructors, and health-promoting school teams. The active role of community and public health nurses in school settings can provide a much needed connection to primary prevention strategies, and it is in this context that nursing learners can contribute to communities while gaining valuable insight on what it means to be a registered nurse. 


\section{References}

Amerson, R. (2010). The impact of service-learning on cultural competence. Nursing Education Perspectives, 31(1), 18-22.

Bandy, J. (2020). What is service learning or community engagement? Vanderbilt University Center for Teaching. https://cft.vanderbilt.edu/guides-sub-pages/teaching-throughcommunity-engagement/

Barnekow, V., Buijs, G., Clift, S., Bruun Jensen, B., Paulus, P., Rivett, D., \& Young, I. (2006). Health-promoting schools: A resource for developing indicators. European Network for Health Promoting Schools. http://www.euro.who.int/_data/assets/pdf_file/0017/240344/E89735.pdf

Canadian Association of Schools of Nursing. (2010, February). Guidelines for quality community health nursing clinical placements for baccalaureate nursing students. https://www.casn.ca/2014/12/guidelines-quality-community-health-nursing-clinicalplacements/

Carnicelli, S., \& Boluk, K. (2017). The promotion of social justice: Service learning for transformative education. Journal of Hospitality, Leisure, Sport \& Tourism Education, 21, 126-134. https://doi.org/10.1016/j.jhlste.2017.01.003

Clarke, V., \& Braun, V. (2013). Teaching thematic analysis: Overcoming challenges and developing strategies for effective learning. The Psychologist, 26(2), 120-123.

Cohen, S. S., \& Milone-Nuzzo, P. (2001). Advancing health policy in nursing education through service learning. Advances in Nursing Science, 23(3), 28-40.

Groh, C. J., Stallwood, L. G., \& Daniels, J. J. (2011). Service-learning in nursing education: Its impact on leadership and social justice. Nursing Education Perspectives, 32(6), 400-406.

Guyon, A., Hancock, T., Kirk, M., MacDonald, M., Neudorf, C., Sutcliffe, P., Talbot, J., \& Watson-Creed, G. (2017). The weakening of public health: A threat to population health and health care system sustainability. Canadian Journal of Public Health, 108(1), e1-e6. https://doi.org/10.17269/CJPH.108.6143

Horn, M. B., Freeland, J., \& Butler, S. M. (2015). Schools as community hubs: Integrating support services to drive educational outcomes. Discussion Papers on Building Healthy Neighborhoods, 3.

Joint Consortium for School Health. (2020). Comprehensive school health framework. What is comprehensive school health? https://www.jcsh-cces.ca/about-us/comprehensive-schoolhealth-framework/

Juniarti, N., Zannettino, L., Fuller, J., \& Grant, J. (2017). Defining service learning in nursing education: An intergrative review. JKP (Jurnal Keperawatan Padjajaran), 4(2), 200212.

Kirk, M. E. (2020). When it is no longer your call: Managing the eroding public health nurse role [Doctoral dissertation, University of Victoria]. UVicSpace. http://hdl.handle.net/1828/11785 
Laliberte, S., Amarshi, Z., Bennett, R., Brunt, C., Fukuyama, K., Gomez, N., Jones, E., Littman, D., McCarthy-Flynn, M., \& Martin, M. (2017). Evaluation of a college-community approach to developing multi-level primary health care-population health promotion practicums for nursing students. Quality Advancement in Nursing Education-Avancées en formation infirmière, 3(2), 4.

Lau, Y., \& Wang, W. (2014). Development and evaluation of a learner-centered educational summer camp program on soft skills for baccalaureate nursing students. Nurse Educator, 39(5), 246-251. https://doi.org/10.1097/nne.0000000000000065

Leh, S. (2011). Nursing students' preconceptions of the community health clinical experience: Implications for nursing education. Journal of Nursing Education, 50(11), 620-627. https://doi.org/10.3928/01484834-20110729-01

Murphy, F., Rosser, M., Bevan, R., Warner, G., \& Jordan, S. (2012). Nursing students' experiences and preferences regarding hospital and community placements. Nurse Education in Practice, 12(3), 170-175. https://doi.org/https://doi.org/10.1016/j.nepr.2011.12.007

Murray, B. S. (2013). Service-learning in baccalaureate nursing education: A literature review. Journal of Nursing Education, 52(11), 621-626.

Newman, M. A., Smith, M. C., Pharris, M. D., \& Jones, D. (2008). The focus of the discipline revisited. Advances in Nursing Science, 31(1), E16-E27. https://doi.org/10.1097/01.ANS.0000311533.65941.f1

O'Brien King, M., \& Gates, M. F. (2007). Teaching holistic nursing: The legacy of Nightingale. Nursing Clinics of North America, 42(2), 309-333. https://doi.org/https://doi.org/10.1016/j.cnur.2007.03.007

Schofield, R., Allan, M., Jewiss, T., Hunter, A., Sinclair, N., Diamond, A., \& Sidwell, C. (2013). Knowing self and caring through service learning. International Journal of Nursing Education Scholarship, 10(1), 267-274.

Shelton, R., \& Harrison, F. (2011). Community placement myths. Primary Health Care, 21(2), 26-28.

Spurr, S., Bally, J., Bullin, C., \& Trinder, K. (2017). Type 2 diabetes in Canadian Aboriginal adolescents: Risk factors and prevalence. Journal of Pediatric Nursing: Nursing Care of Children and Families, 36, 111-117. https://doi.org/10.1016/j.pedn.2017.05.011

Thomas, M. H., \& Smith, R. S. (2017). Building community engagement: Incorporating of service learning in nursing curriculum. Nurse Education Today, 52, 63-65. https://doi.org/ doi:10.1016/j.nedt.2017.01.013

Vogt, M. A., Chavez, R., \& Schaffner, B. (2011). Baccalaureate nursing student experiences at a camp for children with diabetes: The impact of service-learning model. Pediatric Nursing, 37(2), 69-73.

World Health Organization. (1997). Promoting health through schools. Report of a WHO expert committee on comprehensive school health education and promotion (WHO Technical Report Series 870). 
Quality Advancement in Nursing Education - Avancées en formation infirmière, Vol. 7, Iss. 1 [2021], Art. 4

Worrell-Carlisle, P. J. (2005). Service-learning: A tool for developing cultural awareness. Nurse Educator, 30(5), 197-2002. 